\title{
Title: Efficient Electrosynthesis of White Phosphorus from Molten Condensed Phosphate Salts
}

\author{
Authors: Jonathan F. Melville ${ }^{1 \dagger}$, Andrew J. Licini ${ }^{1 \dagger}$, Yogesh Surendranath ${ }^{1 *}$
}

\author{
Affiliations: \\ ${ }^{1}$ Department of Chemistry, Massachusetts Institute of Technology; Cambridge MA 02139, \\ United States. \\ *Corresponding author. Email: yogi@mit.edu. \\ $\uparrow$ These authors contributed equally to this work.
}

\begin{abstract}
Elemental white phosphorus $\left(\mathrm{P}_{4}\right)$ is a crucial feedstock for the entire phosphorusderived chemicals industry, spanning everything from herbicides to food additives. Currently, industrial $\mathrm{P}_{4}$ production is gated by the infrastructurally demanding reduction of phosphate rock by carbon coke in an arc furnace at temperatures of up to $1500{ }^{\circ} \mathrm{C}$. The electrochemical reduction of phosphate salts could enable the sustainable, point-of-use manufacture of white phosphorus; however, such $\mathrm{P}_{4}$ electrosynthesis requires the rapid activation of strong $\mathrm{P}-\mathrm{O}$ bonds. Herein, we show that the intrinsic oxide-accepting character of phosphoryl anhydride linkages in molten condensed phosphate salts promotes the reduction of phosphate to white phosphorus at high electron and energy efficiencies. These findings could enable an efficient, low-carbon alternative to legacy carbothermal synthesis of $\mathrm{P}_{4}$.
\end{abstract}

One-Sentence Summary: Anhydride-promoted electroreduction of molten phosphates may decarbonize production of the critical industrial reagent $\mathrm{P}_{4}$. 


\section{Main Text:}

The carbothermal reduction of phosphate rock to white phosphorus $\left(\mathrm{P}_{4}\right)$ underpins the production of nearly all phosphorus fine chemicals, from the ubiquitous herbicide glyphosate to the foodgrade phosphoric acid in a can of soda (Fig. 1). Due to the extreme conditions of reaction, requiring temperatures of up to $1500{ }^{\circ} \mathrm{C}$, the so-called "thermal process" for $\mathrm{P}_{4}$ production is highly capitalintensive and singlehandedly constitutes a significant fraction of the energy demand and carbon emissions of the global phosphorus economy (1). These high capital costs contribute to the centralized nature of $\mathrm{P}_{4}$ synthesis, necessitating the hazardous international transport of this highly toxic and pyrophoric material. Despite impressive recent advances toward bypassing the intermediacy of $\mathrm{P}_{4}$ to phosphorus chemicals $(2,3)$, the entrenched central role of $\mathrm{P}_{4}$ in the phosphorus economy motivates the development of greener routes to this versatile chemical precursor. The direct electrolysis of phosphate salts to white phosphorus could enable the pointof-use generation of $\mathrm{P}_{4}$ powered by renewable electricity. Herein, we demonstrate that the reduction of molten condensed phosphate salts at low-cost graphite electrodes generates $\mathrm{P}_{4}$ at high electron and energetic efficiencies.

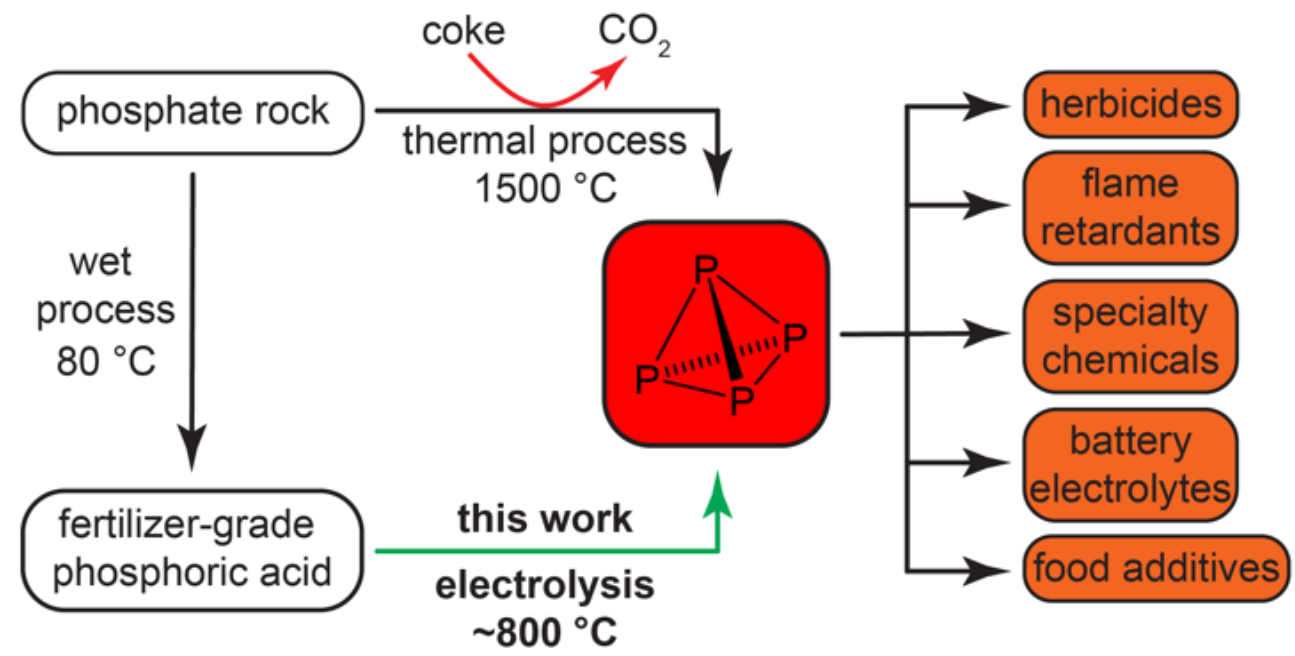

Fig. 1. White phosphorus, $\mathrm{P}_{4}$, is a precursor to a diversity of phosphorus fine chemicals (right) and is prepared by high-temperature carbothermal synthesis (top). We present here an electrosynthetic route (green) to $\mathrm{P}_{4}$ from fertilizer-grade phosphoric acid that can be powered by renewable electricity.

The legacy thermal process (Fig. 1, top; Equation 1) for $\mathrm{P}_{4}$ production is plagued by numerous systemic inefficiencies which are intrinsic to the carbothermal reduction reaction.

$$
2 \mathrm{Ca}_{3}\left(\mathrm{PO}_{4}\right)_{2}+6 \mathrm{SiO}_{2}+10 \mathrm{C} \rightarrow 6 \mathrm{CaSiO}_{3}+10 \mathrm{CO}+\mathrm{P}_{4}(\mathbf{1})
$$

Sufficiently softening the reactant minerals requires the use of an energy-intensive arc furnace, wherein the necessary temperatures of reaction are accessed by Ohmic heating at current densities of up to $5 \mathrm{~A} \cdot \mathrm{cm}^{-2}$. At these temperatures, carbon dioxide reacts irreversibly with $\mathrm{P}_{4}$, and so the thermal process instead only partially oxidizes coke to carbon monoxide, which is subsequently burned off to generate additional heat. This represents a utilization of just two of the potential four reducing electron equivalents per carbon atom (4-6). Furthermore, in order to maintain charge and atom balance as the anionic and oxidic phosphate is converted to elemental phosphorus, silicon dioxide performs an essential role as an oxide acceptor, abstracting oxide equivalents from the phosphate reactant and precipitating as $\mathrm{CaSiO}_{3}$. The heat content of this metasilicate slag is 
responsible for approximately $30 \%$ of the energy consumption by the overall process, a sunk cost whose elimination has long been considered an intractable challenge $(1,5,6)$. Moreover, this slag often accumulates radioactive and toxic heavy element impurities from the raw phosphate rock, complicating its safe disposal (7-11). Due to these challenges, thermal process $\mathrm{P}_{4}$ plants are few and far between: only one such factory can be found in the entire Western hemisphere, with the majority of white phosphorus production relegated to regions (particularly in Africa and Asia) with comparatively loose environmental standards. In 2017, this consolidation induced the importdependent European Union to add $\mathrm{P}_{4}$ to its list of "critical raw materials" $(12,13)$. For these many reasons, new technologies for the downscaled production of $\mathrm{P}_{4}$ could dramatically alter the global supply chain and environmental footprint of this crucial resource.

Although white phosphorus is a vital intermediate towards phosphorus fine chemicals, its production consumes less than 5\% of all extracted phosphate rock; the remaining $95 \%$ is treated with sulfuric acid in order to produce fertilizer-grade phosphoric acid via the "wet process" (Fig. 1) $(14,15)$. As a result, any $\mathrm{P}_{4}$ production route capable of harnessing phosphoric acid as a starting material could leverage the well-established global infrastructure for phosphate fertilizer production and distribution. These considerations motivated us to investigate greener alternatives to the incumbent thermal process, thereby enabling point-of-use synthesis to mitigate the transportation hazards and resource demands of legacy $\mathrm{P}_{4}$ manufacture.

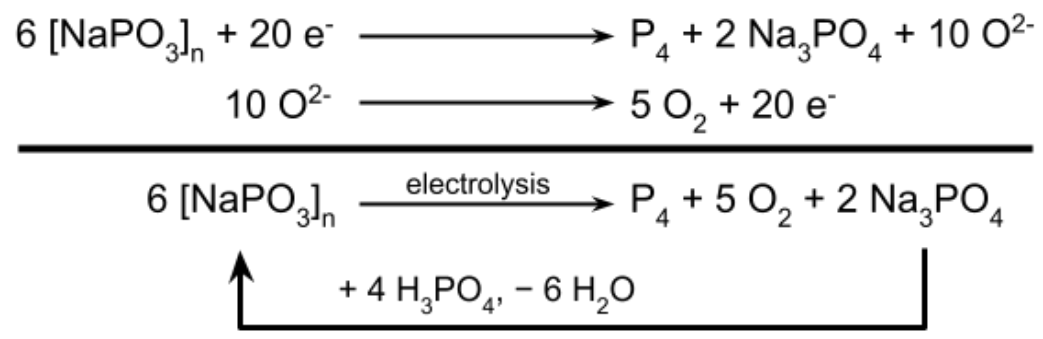

Scheme 1. Half-reaction and overall electrolysis scheme for metaphosphate electrolysis and regeneration.

Akin to the Hall process for aluminum synthesis, the net 20-electron reduction of phosphates to white phosphorus (henceforth PRR) can, in principle, be driven electrochemically. Condensed phosphate salts are in particular promising starting materials for electrolytic $\mathrm{P}_{4}$ evolution: they have modest melting temperatures $\left(628^{\circ} \mathrm{C}\right.$ for sodium metaphosphate), are readily accessible from wet-process phosphoric acid, are free of protic moieties that would induce parasitic hydrogen evolution (a pervasive problem for reductive electrocatalysis), and are themselves intrinsic oxide acceptors through their phosphoryl anhydride linkages. As pictured in Scheme 1, a putative electrolysis reaction of sodium metaphosphate $\left[\mathrm{NaPO}_{3}\right]_{\mathrm{n}}$ would generate $\mathrm{P}_{4}, \mathrm{O}_{2}$, and $\mathrm{Na}_{3} \mathrm{PO}_{4}$. Introduction and subsequent thermal dehydration of phosphoric acid could then regenerate the phosphoryl anhydride linkages, in net effecting the electrolysis of phosphoric acid to white phosphorus, oxygen, and water (Equation 2).

$$
4 \mathrm{H}_{3} \mathrm{PO}_{4} \rightarrow \mathrm{P}_{4}+6 \mathrm{H}_{2} \mathrm{O}+5 \mathrm{O}_{2}(2)
$$

Due to the intrinsic separation of cathodic and anodic half-reactions in an electrochemical cell, this approach enables the segregation of the highly oxophilic $\mathrm{P}_{4}$ generated at the cathode from the oxygen evolved at the anode. Even in the limit that carbon oxidation is used as the anodic reaction, the produced $\mathrm{CO}_{2}$ is isolated from the reactive product, potentially halving the carbon footprint relative to the thermal process. 
Historically, the electrolysis of molten metaphosphates has been investigated in the context of a potential flux for metal electrodeposition (16-25), although research in this area was largely abandoned in the early 1970s. While the electroreduction of metaphosphates was observed with concomitant evolution of $\mathrm{P}_{4}$, these studies provide few quantitative insights or synthetic handles for maximizing the efficiency or selectivity of phosphate reduction, limiting the development of practical phosphorus electrosynthesis technologies. Owing to the complexities of precise electroanalysis in this exotic reaction medium - and, presumably, minimal contemporaneous environmental incentive to decarbonize the incumbent thermal process - these knowledge gaps persist to the present day. A resurgent interest in low-carbon $\mathrm{P}_{4}$ synthesis has brought forth a recent report in which orthophosphates are electrolyzed in a calcium chloride melt (26); however, numerous factors limit the industrial viability of this system, including a low orthophosphate solubility in the reaction medium $\left(3\right.$ mass $\%$ at $800{ }^{\circ} \mathrm{C}$ ), the possibility of undesired chloride oxidation and subsequent chlorocarbon formation at the anode $(27,28)$, and a lack of oxidetransporting moieties to mediate stoichiometric balance with the anodic reaction. By comparison, condensed phosphate salts are composed entirely of electrochemically active phosphate species, enabling high diffusion-limited current densities without competing reactivity. We additionally theorized that the oxide-accepting character of the native phosphoryl anhydride linkages in condensed phosphate melts could play a powerful promoting role in fostering low-overpotential $\mathrm{P}_{4}$ electrosynthesis. To test this hypothesis, we developed for the first time a rigorous set of electroanalytical methodologies for quantifying reaction selectivity and efficiency in this unconventional electrolyte, and employed these tools to elucidate the governing attributes which underpin efficient $\mathrm{P}_{4}$ electrosynthesis.

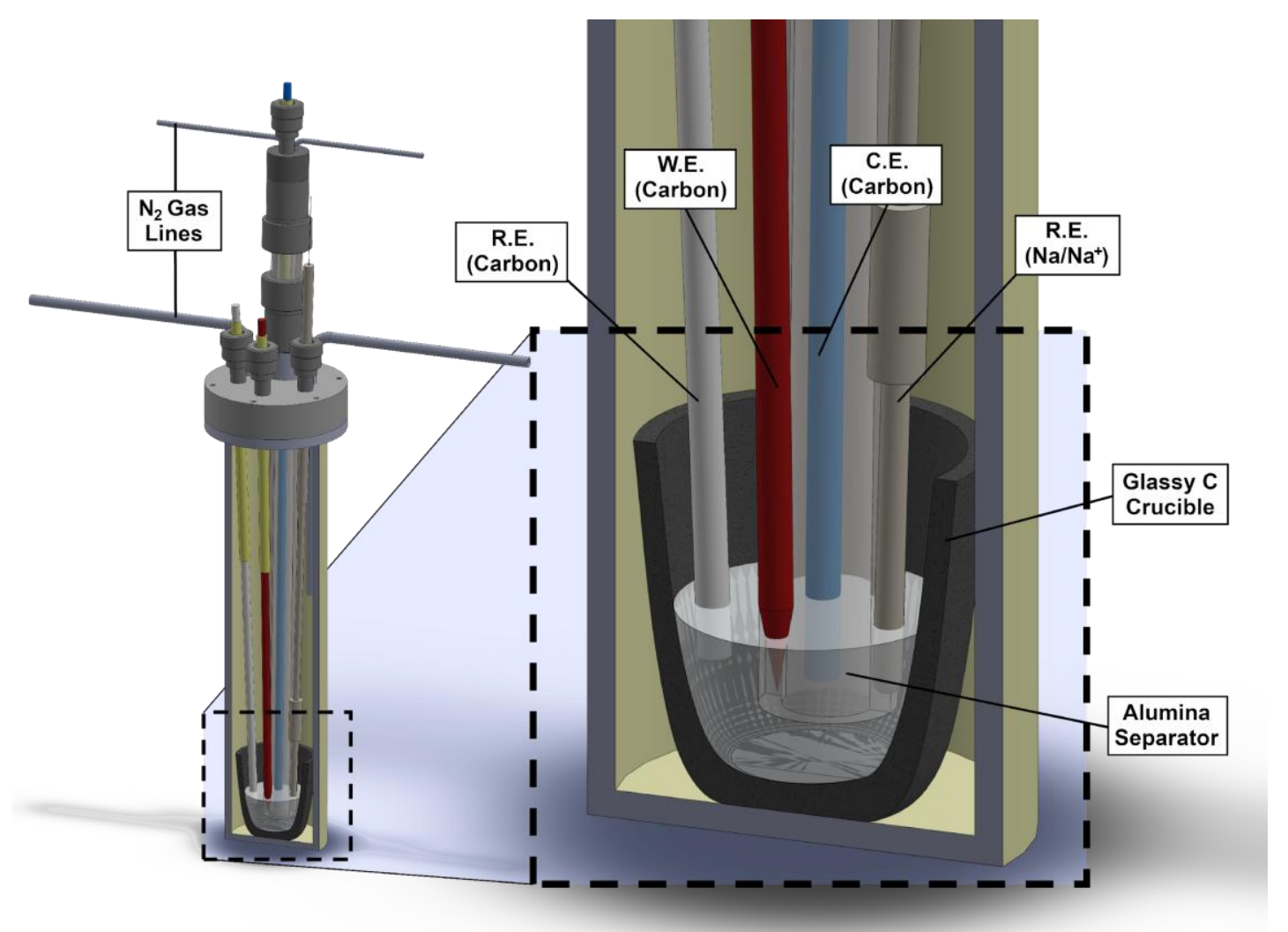

Fig. 2. Cutaway schematic of high-temperature electrochemical cell featuring separated working 
and counter chambers and a Na/Na ${ }^{+}$reference electrode. W.E. $=$working electrode; R.E. $=$ reference electrode; C.E. = counter electrode.

We began by constructing a robust system for quantitative high-temperature electroanalysis and mechanistic investigation of molten salt electrolysis (Fig. 2 \& Figs. S1-S4). Our cell included separated anodic and cathodic chambers with independent $\mathrm{N}_{2}$ flow streams, a $\mathrm{Na} / \mathrm{Na}^{+}$electrode for use as a fixed-potential reference, and a cold trap to enable product characterization and quantification. Graphite rods were used for all electrodes in a standard 3-electrode analytical setup (working, counter, and reference). Whereas many transition metals readily form metal phosphide alloys $(29,30)$, carbon is highly immiscible with phosphorus $(31,32)$; accordingly, we found graphite to be stable under cathodic conditions, displaying no significant changes in mass nor surface area under any conditions examined in this study. By comparison, the alumina-body $\mathrm{Na} / \mathrm{Na}^{+}$reference electrode was subject to corrosion upon prolonged exposure to the melt, and so it was instead used to calibrate a graphite pseudoreference electrode, the two comprising a quasireference electrode pair (Fig. S5) (33). Since these studies focus on the cathodic half-reaction, our setup employed a sacrificial graphite counter electrode which underwent oxidation principally to $\mathrm{CO}_{2}$, as determined by $\mathrm{GC}$ analysis. Robust reactor design is a significant impediment to reproducible electrochemistry at high temperatures, and as such we provide in our Supplementary Materials full specifications and part numbers for construction of the molten salt electrolysis system employed in these studies.
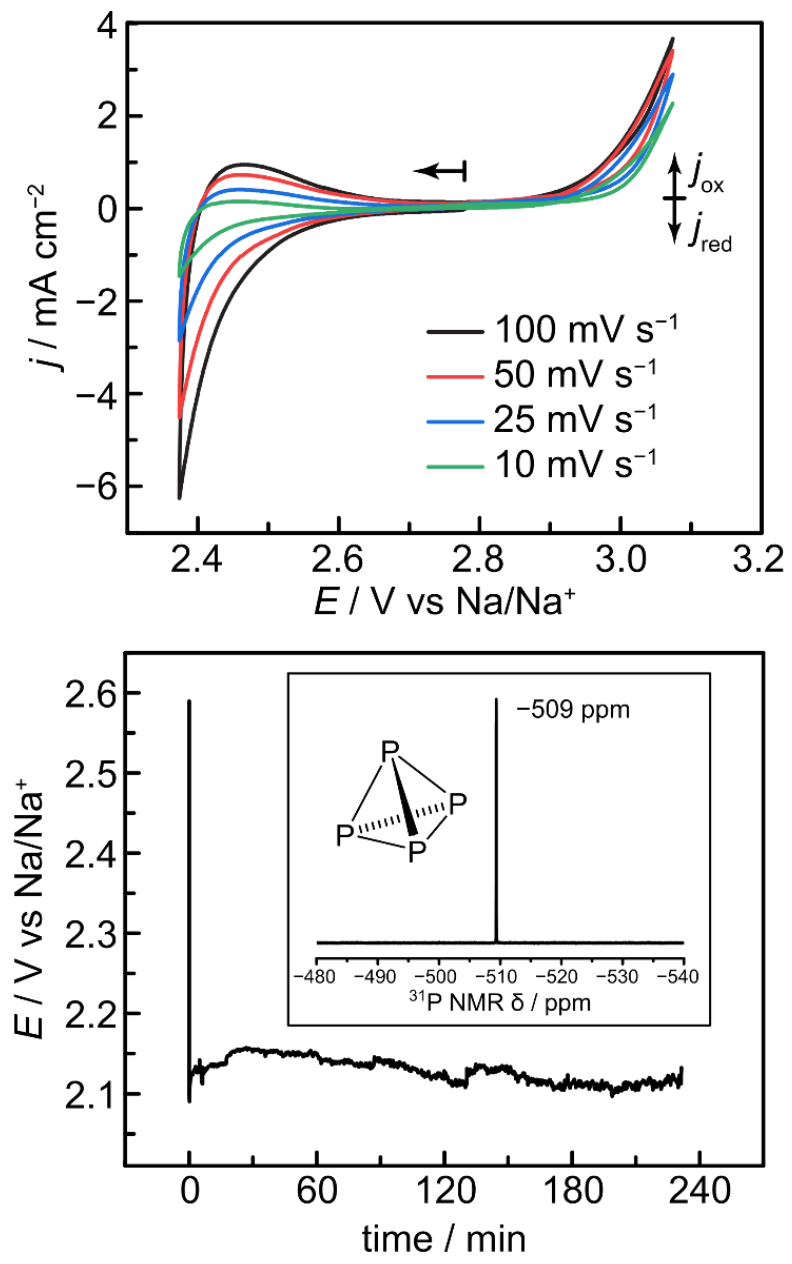

Fig. 3. (top) Cyclic voltammograms of a graphite electrode in molten sodium trimetaphosphate 
at $800{ }^{\circ} \mathrm{C}$. Arrow indicates point of initiation and direction of scan. (bottom)

Chronopotentiometry trace of molten sodium trimetaphosphate electrolysis at a current density of $48 \mathrm{~mA} \cdot \mathrm{cm}^{-2}$. (bottom, inset) ${ }^{31} \mathrm{P}$ NMR spectrum of electrogenerated $\mathrm{P}_{4}$ dissolved in $\mathrm{CS}_{2}$.

Using this molten salt electroanalytical setup, we investigated the electrochemical behavior of molten sodium trimetaphosphate using cyclic voltammetry (CV), as seen in Fig. 3. To mitigate the effects of bubble formation and associated occlusion of the electrode surface area, we employed a graphite working electrode with a conical tip (Fig. 2, red and Fig. S4b). Voltammetric data reveal the onset of substantial reductive current at approximately $+2.4 \mathrm{~V}$ against a Na/ $\mathrm{Na}^{+}$reference electrode. As our electrolyte is itself our reactant, this cathodic wave does not peak; rather, we observe an exponentially rising reductive feature of the type associated with solvent reduction in conventional electrolytes. However, unlike a typical catalytic wave, this cathodic process displays a square-root dependence on scan rate, implying the participation of a diffusion-limited species. Upon reversal of the potential sweep, we observe the immediate appearance of a broad oxidative wave, which we ascribe to a reverse redox process. The peak potential and current magnitude in this anodic wave are also scan rate-dependent; a prominent oxidative feature is observed at 100 $\mathrm{mV} \cdot \mathrm{s}^{-1}$, whereas it is almost nonexistent at $10 \mathrm{mV} \cdot \mathrm{s}^{-1}$. These data are characteristic of the formation and build-up of a transient reduced species at the electrode interface. To further probe the reductive voltammetry, we performed computational CV simulations (Tables S1-S3 \& Figs. S6-S7), which indicated that the voltammetric shape and scan rate dependence could result from diffusion-limited back-oxidation of partially reduced intermediates in a reversible redox process. Finally, at $+3.0 \mathrm{~V}$ vs. $\mathrm{Na} / \mathrm{Na}^{+}$we observe an irreversible anodic feature with minimal scan rate dependence, which we assign to the oxidation of our graphite electrode; prolonged electrolysis at this potential will result in visible corrosion of the otherwise-inert graphite.

Steady-state electrolysis was used to determine the product of electroreduction and the Faradaic efficiency of its formation. Bulk electrolysis at a fixed current density of $48 \mathrm{~mA} \cdot \mathrm{cm}^{-2}$ results in a steady potential of $+2.1 \mathrm{~V}$ vs. Na/ $/ \mathrm{Na}^{+}$(Fig. 3, bottom) over a time scale of hours. Electrolysis in this potential region with sustained flow of $\mathrm{N}_{2}$ gas through the cathode chamber results in the formation of pyrophoric yellow-white crystals (Fig. S8a) in the cold trap. ${ }^{31} \mathrm{P}$ NMR analysis of these waxy crystals in carbon disulfide (Fig. 3b, bottom inset), reveals a single peak at a chemical shift of $-509.4 \mathrm{ppm}$ vs an $85 \% \mathrm{H}_{3} \mathrm{PO}_{4}$ reference, which is highly characteristic of white phosphorus (34). If the glass trap is not lined with aluminum foil, these crystals will slowly decay over the course of several hours into a reddish-brown coating (Fig. S8b), consistent with the photoconversion of molecular white phosphorus to polymeric red phosphorus. Additional accumulations of red phosphorus accrete on tubing and surfaces near the reactor head (Fig. S9). Red and white phosphorous residues in the trap and associated transfer lines were oxidized with bleach for quantification by ${ }^{31} \mathrm{P}$ NMR against an internal standard (Figs. S10-S11). While the isolated yield of volatilized phosphorus products is highly dependent on the integrity of the O-ring reactor seals at temperature, we observe under optimal conditions a peak isolated yield of elemental phosphorus of $64.5 \%$ relative to the charge passed, for the four-hour galvanostatic electrolysis pictured in Fig. 3. Accounting for the $68 \%$ reactor gas-flow retention rate (thereby accounting for $\mathrm{P}_{4}$ losses from gas leakage), this isolated yield corresponds to a Faradaic yield of $95 \%$ for $\mathrm{P}_{4}$ evolution. We note that this gas leakage is attributed to the poor thermal stability of the perfluoroelastomer O-ring seals employed in our laboratory-scale electrochemical setup; incumbent electrochemical devices (such as solid-oxide electrolyzers) utilize metal, ceramic, and/or glass based seals that are stable to higher temperatures and pressures than those demanded in this process (35), and thus, we envision that increased gas collection efficiency can be realized 
with improved engineering of a larger scale reactor. Collectively, our data suggest that under these conditions, $\mathrm{P}_{4}$ is the predominant cathodic product of metaphosphate electrolysis.

As there exists a paucity of thermochemical reference data on condensed phosphate melts, a theoretical energetic efficiency for this process cannot be readily calculated, and must instead be measured empirically. In particular, we must establish the excess energy or overpotential, $\eta$, required to drive PRR in this system relative to the thermodynamic minimum. Calculating $\eta$ requires knowledge of the thermodynamic equilibrium reduction potential $E_{\text {eq }}$ for the $\mathrm{P}^{\mathrm{V}}$ to $\mathrm{P}^{(0)}$ redox couple under the conditions of our electrolysis, as the former is defined in terms of the latter: $E=E_{\text {eq }}+\eta$. Insight into the equilibrium potential of the reaction requires a direct probe of this minimum potential at which the reverse oxidation of $\mathrm{P}^{(0)}$ to $\mathrm{P}^{\mathrm{V}}$ can occur; however, our cathodic product, white phosphorus, rapidly escapes from the electrode interface due to its gaseous nature at the temperature of reaction. To increase the residency time of the $\mathrm{P}^{(0)}$ product, we employed a graphite cathode with a concave depression capable of trapping a $\mathrm{P}_{4}$ bubble (Fig. S4c), with the aim of establishing a $\mathrm{PO}_{3}{ }^{-} \rightleftharpoons \mathrm{P}_{4}$ equilibrium at the graphite-metaphosphate-phosphorus triplephase boundary. For an electrode that can catalyze both anodic and cathodic half-reactions, the open-circuit potential (OCP) recorded in the presence of reactant and product provides an estimate of the equilibrium potential $E_{\mathrm{eq}}$ for the reaction (36).

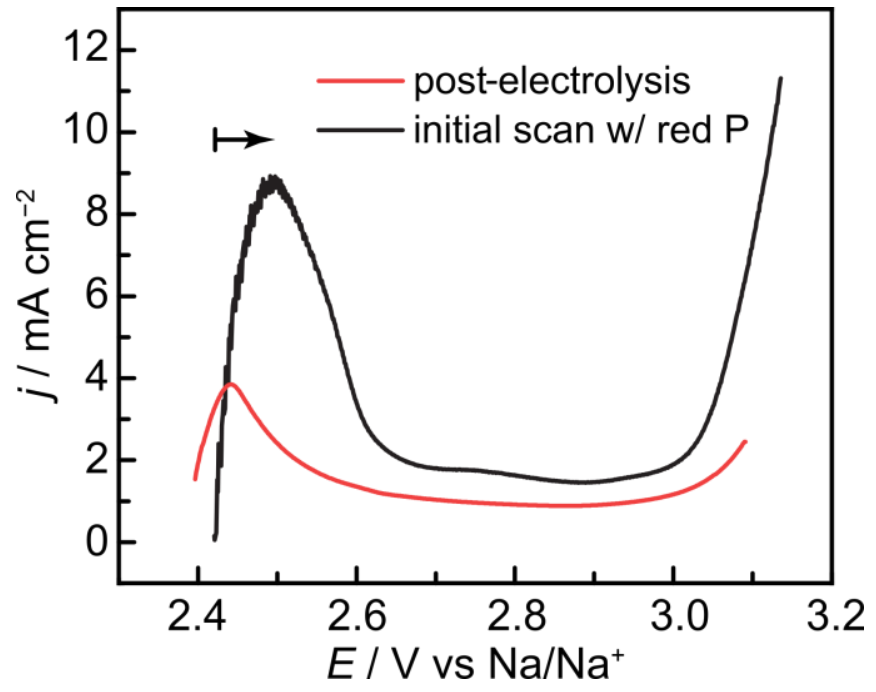

Fig. 4. Linear-sweep voltammograms scanning oxidatively from OCP at $100 \mathrm{mV} \cdot \mathrm{s}^{-1}$ with hollowed graphite electrodes containing electrosynthesized (red) and chemically generated (black) $\mathrm{P}_{4}$.

We implemented this approach by galvanostatically generating a $\mathrm{P}_{4}$ bubble in the hollow of our working electrode and performing a linear-sweep voltammogram scanning oxidatively from the OCP (Fig. 4, red trace). We observe an anodic peak at approximately $+2.45 \mathrm{~V} \mathrm{vs}$. Na/ $\mathrm{Na}^{+}$, analogous to that seen in our cyclic voltammogram and with similar scan rate dependence (Fig. S14). This indicates that our concave electrode is capable of trapping comparatively long-lived partially reduced species at the interface, as well as subsequently reoxidizing these species. While highly suggestive that the voltammetric feature at $+2.45 \mathrm{~V} \mathrm{vs}$. $\mathrm{Na} / \mathrm{Na}^{+}$corresponds to $\mathrm{P}_{4}$ oxidation, this evidence does not by itself confirm that white phosphorus, or a species in a rapid chemical equilibrium with white phosphorus, is the source of anodic current. To further probe the nature of the oxidative wave, we conducted a product dosing experiment by exploiting the thermal depolymerization of red phosphorus to white phosphorus. We loaded the cavity of a hollowed graphite electrode with red phosphorus (Fig. S15) and performed an analogous oxidative LSV 
sweep as soon as it was lowered into the electrolyte, exposing the electrode to non-Faradaically generated $\mathrm{P}_{4}$ and allowing us to directly probe the required potential for back-oxidation in this system. With this red phosphorus-dosed electrode, we observe an open-circuit potential of $2.38 \mathrm{~V}$ vs. $\mathrm{Na} / \mathrm{Na}^{+}$(Fig. S16), and an oxidative scan from this potential reveals a large anodic wave we attribute to the reoxidation of $\mathrm{P}_{4}$ to phosphate (Fig. 4, black trace). These data allow us to estimate a $\mathrm{PO}_{3}{ }^{-} \rightleftharpoons \mathrm{P}_{4}$ equilibrium potential of approximately $2.4 \mathrm{~V}$ vs. $\mathrm{Na} / \mathrm{Na}^{+}$in a metaphosphate melt, and highlight that $\mathrm{P}_{4}$ electrogeneration occurs near the thermodynamic limit under these conditions.

As previously mentioned, the reduction of $\mathrm{PO}_{3}{ }^{-}$to $\mathrm{P}_{4}$ must necessarily generate oxide equivalents, which are consumed in this system via cleavage of phosphoryl anhydride linkages in the electrolyte (Fig. S18). To assess the kinetic role of phosphoryl anhydride in facilitating PRR, we synthesized a series of melts of varying anhydride concentration, ranging from $5.4 \mathrm{~mol} \cdot \mathrm{kg}^{-1}$ to $9.8 \mathrm{~mol} \cdot \mathrm{kg}^{-1}$, by dissolving sodium orthophosphate in pure sodium trimetaphosphate. These concentrations were chosen to correspond to the anhydride concentrations of pure sodium tripolyphosphate, tetrapolyphosphate, decapolyphosphate, and metaphosphate (Table S6). We then examined the electrochemical behavior of these melts by cyclic voltammetry and chronopotentiometry.
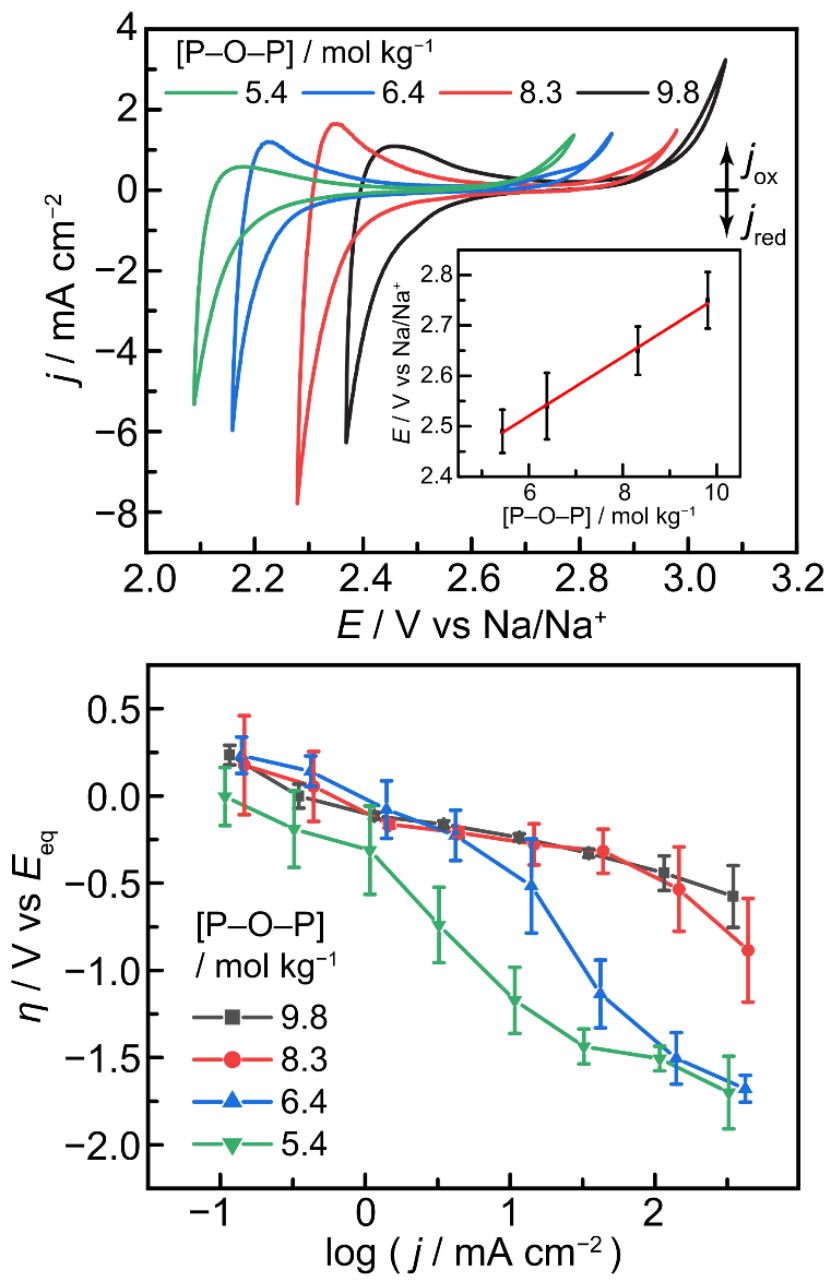

Fig. 5. (top) Cyclic voltammograms (scan rate $=100 \mathrm{mV} \cdot \mathrm{s}^{-1}$ ) of condensed sodium phosphate melts. $[\mathrm{P}-\mathrm{O}-\mathrm{P}]$ denotes the molal concentration of phosphoryl anhydride linkages in the melt, 
corresponding in decreasing order to the anhydride concentrations of pure sodium metaphosphate, decapolyphosphate, tetrapolyphosphate, and tripolyphosphate melts. (top, inset) Plot of graphite pseudoreference open-circuit potentials against an $\mathrm{Na} / \mathrm{Na}^{+}$reference electrode as a function of phosphoryl anhydride linkage concentration. Error bars represent $95 \%$ confidence intervals as collected from three independent experimental setups. (bottom) Plot of phosphate reduction overpotential as a function of chronopotentiometric current density in sodium trimetaphosphate, decapolyphosphate, tetrapolyphosphate, and tripolyphosphate melts. Error bars represent $95 \%$ confidence intervals of a set of three independent experimental setups, each setup itself being performed in triplicate, for a total of nine data points.

Compared against a carbon pseudoreference electrode, the voltammetric features roughly overlay across all electrolyte compositions examined. However, as the melt anhydride concentration decreases, the graphite pseudoreference potentials display a progressive cathodic shift relative to an anhydride-independent $\mathrm{Na} / \mathrm{Na}^{+}$reference (Fig. 5, top inset). To account for this shift, CV data across these electrolytes are plotted on a common $\mathrm{Na} / \mathrm{Na}^{+}$reference scale (Fig. 5 top). These data reveal a cathodic shift in the PRR wave by $\sim 250 \mathrm{mV}$ as the anhydride concentration decreases from $9.8 \mathrm{~mol} \cdot \mathrm{kg}^{-1}$ to $5.4 \mathrm{~mol} \cdot \mathrm{kg}^{-1}$. In effect, as the basicity of the medium rises with decreasing anhydride fraction, increasingly negative potentials are required to drive PRR - analogous to the negative potential shift observed for proton-coupled electrochemical reactions in water as the $\mathrm{pH}$ increases. This negative shift is also observed for the anodic oxidation of carbon, indicating that it too is sensitive to the oxide content of the melt. Given the systematic nature of these potential shifts, we stress that this phenomenon is only apparent upon referencing against an anhydride-independent $\mathrm{Na} / \mathrm{Na}^{+}$electrode. These data highlight that molten metaphosphate electrolysis is highly sensitive to the anhydride population in the melt, providing a valuable handle that can be tuned to optimize the efficiency and durability of $\mathrm{P}_{4}$ electrosynthesis.

The critical role of phosphoryl anhydride linkages is also reflected in the steady-state currentoverpotential (Tafel) behavior of the system. In pure trimetaphosphate melts (Fig. 5 bottom, black trace), we observe a roughly log-linear scaling in current and overpotential across a range of 3.5 orders of magnitude in current density, with current densities in excess of $300 \mathrm{~mA} \cdot \mathrm{cm}^{-2}$ accessible at modest overpotentials of $500 \mathrm{mV}$. Phosphorus production at this cell potential with a graphite anode would correspond to an electrical energy requirement of $\sim 4.3 \mathrm{kWh} / \mathrm{kg} \mathrm{P}$, a value which rises modestly to $\sim 5.8 \mathrm{kWh} / \mathrm{kg}$ when accounting for additional heat inputs and assuming conservative heat recovery efficiencies (Tables S7-S8). This total energy cost compares favorably with the optimized industrial energy requirement of $12.5-14 \mathrm{kWh} / \mathrm{kg} \mathrm{P} 4$ for the thermal process $(1$, 7). In the pure metaphosphate melt we observe a Tafel slope of $150 \mathrm{mV} \cdot \mathrm{dec}^{-1}$, corresponding to an empirical transfer coefficient of $b \approx 1.4$. This accords with an ideal transfer coefficient of 1.5 , for a mechanism involving a reversible one-electron transfer followed by a rate-limiting oneelectron transfer step $(37,38)$. In the context of phosphate reduction, a mechanistic sequence involving quasi-equilibrium $\mathrm{P}^{\mathrm{V}}$ to $\mathrm{P}^{\mathrm{IV}}$ reduction, followed by rate-limiting $\mathrm{P}^{\mathrm{IV}}$ to $\mathrm{P}^{\mathrm{III}}$ reduction, would be consistent with the observed Tafel behavior. This electrogenerated $\mathrm{P}^{\mathrm{III}}$ species may then proceed to $\mathrm{P}^{(0)}$ via rapid electroreduction or disproportionation (39).

The observed Tafel behavior is strongly dependent on the anhydride population in the melt. Within error, the Tafel plots overlay at low overpotential, but a progressive deviation from linearity is observed at higher overpotentials and current densities as the melt anhydride population is locally depleted (black to red to blue to green in Fig. 5, bottom). For the melts with the lowest anhydride population, the Tafel plots recoalesce at a $-1.5 \mathrm{~V}$ overpotential. In line with literature reports and thermochemical reference data, we impute this high overpotential region to the 
reduction of orthophosphate $(23,24,40-46)$. Thus, we attribute this transition in the Tafel behavior to the local consumption of anhydrides near the electrode surface, a phenomenon that occurs at lower current densities for melts with lower bulk anhydride concentrations. Analogous to prior reports of Lewis acid-promoted reduction of organophosphine oxides (47), the data evince that the anhydride linkages in these melts function as preassociated Lewis acids, promoting $\mathrm{P}-\mathrm{O}$ cleavage and thereby reducing the overpotential for $\mathrm{P}_{4}$ synthesis by nearly a full volt.

White phosphorus remains a versatile precursor to numerous value-added chemicals, yet its synthesis has long been inextricable from the inefficient and intrinsically carbonaceous thermal process. With this work, we take a step towards a sustainable alternative that can employ wet process-derived condensed phosphates to generate $\mathrm{P}_{4}$ at high atom and energy efficiencies. By exploiting the intrinsic oxide-accepting character of these melts, we obviate the pernicious inefficiencies associated with slag formation in the incumbent thermal process. The ubiquitous starting material and comparatively mild conditions of electrosynthesis present the attractive possibility of point-of-use $\mathrm{P}_{4}$ generation at existing fine chemical factories, mitigating the need for transport and storage of this hazardous substance. Even with a carbon anode, such electrosynthesis emits half as much $\mathrm{CO}_{2}$ per molecule of $\mathrm{P}_{4}$ as the incumbent process; the carbon footprint may be further reduced by the incorporation of oxygen-evolving anodes $(19,25)$. Further extending this work to lower-melting condensed phosphate eutectics, such as lithium-potassium metaphosphate $\left(\mathrm{MP} 518^{\circ} \mathrm{C}\right.$ ), could enable a combined concentrated solar thermal/electrochemical approach to carbon-neutral $\mathrm{P}_{4}$ synthesis powered solely by renewable energy sources $(21,48,49)$. In a decarbonized future economy, such electrolytic phosphorus synthesis may one day 'short-circuit' the thermal process entirely.

\section{References and Notes}

1. H. Diskowski, T. Hofmann, in Ullmann's Encyclopedia of Industrial Chemistry (WileyVCH, ed. 7, 2000; https://onlinelibrary.wiley.com/doi/abs/10.1002/14356007.a19_505).

2. M. B. Geeson, C. C. Cummins, Phosphoric acid as a precursor to chemicals traditionally synthesized from white phosphorus. Science. 359, 1383-1385 (2018).

3. M. B. Geeson, C. C. Cummins, Let's Make White Phosphorus Obsolete. ACS Cent. Sci. 6, 848-860 (2020).

4. C. Ponak, Phosphorus Gasification During The Reduction Of Basic Oxygen Furnace Slags In A Novel Reactor Concept. Adv. Mater. Lett. 11, 20071535-20071535 (2020).

5. F. W. Dorn, H. Harnisch, Zur Reduktion von Calciumphosphat, bei der PhosphorHerstellung. Chem. Ing. Tech. 42, 1209-1215 (1970).

6. J. Wisniak, Phosphorus-From Discovery to Commodity. Indian J. Chem. Technol. 12, 108122 (2005).

7. A. R. Jupp, S. Beijer, G. C. Narain, W. Schipper, J. Chris Slootweg, Phosphorus recovery and recycling - closing the loop. Chem. Soc. Rev. 50, 87-101 (2021).

8. K. R. Engels, A. Nieuwhof, J. B. J. Spijkerman, Removal of cadmium from phosphoric acidcontaining solutions (1990), (available at https://patents.google.com/patent/US4975162A/en). 
9. C. A. Grant, S. C. Sheppard, Fertilizer Impacts on Cadmium Availability in Agricultural Soils and Crops. Hum. Ecol. Risk Assess. 14, 210-228 (2008).

10. T. L. Roberts, Cadmium and Phosphorous Fertilizers: The Issues and the Science. Procedia Eng. 83, 52-59 (2014).

11. M. Marini, D. Caro, M. Thomsen, The new fertilizer regulation: A starting point for cadmium control in European arable soils? Sci. Tot. Environ. 745, 140876 (2020).

12. M. Gislev, M. Grohol, "Report on Critical Raw Materials and the Circular Economy" (European Commission, Directorate-General for Internal Market, Industry, Entrepreneurship and SMEs, Luxembourg: Publications Office of the European Union, 2018), (available at http://publications.europa.eu/resource/cellar/d1be1b43-e18f-11e8-b69001aa75ed71a1.0001.01/DOC_1).

13. Deloitte Sustainability, British Geological Survey, Bureau de Recherches Géologiques et Minières, Netherlands Organisation for Applied Scientific Research, Study on the review of the list of Critical Raw Materials: Critical Raw Materials Factsheets (2017), , doi:doi:10.2873/398823.

14. USGS, "Mineral commodity summaries 2021," Mineral Commodity Summaries (Commodity Statistics and Information, U.S. Geological Survey, Reston, VA, 2021), p. 200.

15. FAO, World fertilizer trends and outlook to 2022 (FAO, Rome, Italy, 2019; http://www.fao.org/publications/card/en/c/CA6746EN/).

16. M. Centnerszwer, S. Szper, Bull. Intern. Acad. Polonaise. A, 364-368. (1931).

17. V. N. Andreeva, The decomposition potentials of metallic oxides in fused phosphates. $U k r$. Khim. Zh. 21, 569-575 (1955).

18. P. N. Yocom, thesis, University of Illinois (1958).

19. Yu. K. Delimarskii, V. N. Andreeva, Potentiometric Determination of the Solubility of Metal Oxides in Fused Sodium Metaphosphates. Zh. Neorg. Khim. 5, 1800-1805 (1960).

20. B. A. Gruber, Method for the preparation of pure elemental phosphorus (1960), (available at https://patents.google.com/patent/US2965552A/en?oq=United+States+Patent+Office+2\%2c $965 \% 2 c 552)$.

21. R. D. Caton, H. Freund, Polarography in Fused Alkali Metaphosphates. Anal. Chem. 35, 2103-2108 (1963).

22. H. A. Laitinen, K. R. Lucas, A study of the electro reduction of metaphosphate in molten LiCl-KCl eutectic. J. Electroanal. Chem. 12, 553-563 (1966).

23. E. Franks, D. Inman, The electroreduction of molten phosphates. J. Electroanal. Chem. Interf. Electrochem. 26, 13-26 (1970). 
24. E. Franks, D. Inman, An electroanalytical study of the composition of molten sodium metaphosphate. J Appl Electrochem. 1, 73-78 (1971).

25. E. J. Casey, A. R. Dubois, Étude cinétique de quelques cellules électrochimiques de métaphosphate de sodium $\left(\mathrm{NaPO}_{3}\right)$ fondu. Can. J. Chem. 49, 2733-2745 (1971).

26. X. Yang, T. Nohira, A New Concept for Producing White Phosphorus: Electrolysis of Dissolved Phosphate in Molten Chloride. ACS Sus. Chem. Eng. 8, 13784-13792 (2020).

27. W. Haupin, in Encyclopedia of Physical Science and Technology (Third Edition), R. A. Meyers, Ed. (Academic Press, New York, 2003; https://www.sciencedirect.com/science/article/pii/B0122274105000223), pp. 495-518.

28. A. T. Tabereaux, R. D. Peterson, in Treatise on Process Metallurgy, S. Seetharaman, Ed. (Elsevier, Boston, 2014; https://www.sciencedirect.com/science/article/pii/B9780080969886000237), pp. 839-917.

29. S. Carenco, Y. Hu, I. Florea, O. Ersen, C. Boissière, N. Mézailles, C. Sanchez, MetalDependent Interplay between Crystallization and Phosphorus Diffusion during the Synthesis of Metal Phosphide Nanoparticles. Chem. Mater. 24, 4134-4145 (2012).

30. S. Carenco, D. Portehault, C. Boissière, N. Mézailles, C. Sanchez, 25th Anniversary Article: Exploring Nanoscaled Matter from Speciation to Phase Diagrams: Metal Phosphide Nanoparticles as a Case of Study. Adv. Mater. 26, 371-390 (2014).

31. J. Guan, D. Liu, Z. Zhu, D. Tománek, Two-Dimensional Phosphorus Carbide: Competition between $\mathrm{sp}^{2}$ and $\mathrm{sp}^{3}$ Bonding. Nano Lett. 16, 3247-3252 (2016).

32. X. Ma, J. Zhou, T. Yang, D. Li, Y. P. Feng, Phase diagram and superlattice structures of monolayer phosphorus carbide $\mathrm{P}_{\mathrm{x}} \mathrm{C}_{(1-\mathrm{x})}$. Phys. Rev. Mater. 5, 024005 (2021).

33. G. Inzelt, in Handbook of Reference Electrodes, G. Inzelt, A. Lewenstam, F. Scholz, Eds. (Springer, Berlin, Heidelberg, 2013; https://doi.org/10.1007/978-3-642-36188-3_14), pp. 331-332.

34. A. E. Seitz, F. Hippauf, W. Kremer, S. Kaskel, M. Scheer, Facile storage and release of white phosphorus and yellow arsenic. Nat. Commun. 9, 2-7 (2018).

35. M. K. Mahapatra, K. Lu, Glass-based seals for solid oxide fuel and electrolyzer cells - A review. Materials Science and Engineering: R: Reports. 67, 65-85 (2010).

36. A. J. Bard, L. R. Faulkner, in Electrochemical Methods: Fundamentals and Applications (Wiley, New York, 2nd edition., 2000), pp. 458-464.

37. J. O. Bockris, Z. Nagy, Symmetry factor and transfer coefficient. A source of confusion in electrode kinetics. J. Chem. Educ. 50, 839 (1973). 
38. R. J. Taylor, A. A. Humffray, Electrochemical Studies on Glassy Carbon Electrodes II: Oxygen Reduction in Solutions of High pH (pH 10). J. Electroanal. Chem. 64, 63-84 (1975).

39. D. Liu, X. Li, L. Wei, T. Zhang, A. Wang, C. Liu, R. Prins, Disproportionation of hypophosphite and phosphite. Dalton Trans. 46, 6366-6378 (2017).

40. C. C. Stephenson, R. L. Potter, T. G. Maple, J. C. Morrow, The thermodynamic properties of elementary phosphorus The heat capacities of two crystalline modifications of red phosphorus, of $\alpha$ and $\beta$ white phosphorus, and of black phosphorus from 15 to $300 \mathrm{~K} . J$. Chem. Thermodyn. 1, 59-76 (1969).

41. M. W. Chase, NIST-JANAF Thermochemical Tables, Fourth Edition. J. Phys. Chem. Ref. Data, 1948-1951 (1998).

42. J. D. Cox, D. D. Wagman, V. A. Medvedev, CODATA Key Values for Thermodynamics, 1 (1984).

43. R. J. Irving, H. McKerrell, Standard heats of formation of $\mathrm{NaH}_{2} \mathrm{PO}_{4}, \mathrm{Na}_{2} \mathrm{HPO}_{4}$ and $\mathrm{Na}_{3} \mathrm{PO}_{4}$. Trans. Faraday Soc. 63, 2913-2916 (1967).

44. S. J. Ashcroft, E. Keen, C. T. Mortimer, Thermochemistry of formation of sodium polyphosphates from sodium orthophosphates. Trans. Faraday Soc. 65, 2851-2855 (1969).

45. J. A. Rard, T. J. Wolery, The Standard Chemical-Thermodynamic Properties of Phosphorus and Some of its Key Compounds and Aqueous Species: An Evaluation of Differences between the Previous Recommendations of NBS/NIST and CODATA. J. Solut. Chem. 36, 1585-1599 (2007).

46. P. Vieillard, Y. Tardy, in Phosphate Minerals, J. O. Nriagu, P. B. Moore, Eds. (Springer, Berlin, Heidelberg, 1984; https://doi.org/10.1007/978-3-642-61736-2_4), pp. 171-198.

47. J. S. Elias, C. Costentin, D. G. Nocera, Direct Electrochemical $\mathrm{P}^{(\mathrm{V})}$ to $\mathrm{P}^{(\mathrm{III})}$ Reduction of Phosphine Oxide Facilitated by Triaryl Borates. J. Am. Chem. Soc. 140, 13711-13718 (2018).

48. K. Vignarooban, X. Xu, A. Arvay, K. Hsu, A. M. Kannan, Heat transfer fluids for concentrating solar power systems - A review. Appl. Energy. 146, 383-396 (2015).

49. S. Licht, H. Wu, STEP Iron, a Chemistry of Iron Formation without $\mathrm{CO}_{2}$ Emission: Molten Carbonate Solubility and Electrochemistry of Iron Ore Impurities. J. Phys. Chem. C. 115, 25138-25147 (2011).

50. W. E. Haupin, Electrochemistry of the Hall-Heroult process for aluminum smelting. $J$. Chem. Educ. 60, 279 (1983).

51. S. Prasad, Studies on the Hall-Heroult aluminum electrowinning process. J. Braz. Chem. Soc. 11, 245-251 (2000). 
52. W. B. Frank, W. E. Haupin, H. Vogt, M. Bruno, J. Thonstad, R. K. Dawless, H. Kvande, O. A. Taiwo, in Ullmann's Encyclopedia of Industrial Chemistry (Wiley-VCH, 2009; https://onlinelibrary.wiley.com/doi/abs/10.1002/14356007.a01_459.pub2).

53. F. H. Campbell, Contributions to the chemistry of gold. Trans. Faraday Soc. 3, 103-113 (1907).

54. S. Cherevko, A. A. Topalov, A. R. Zeradjanin, I. Katsounaros, K. J. J. Mayrhofer, Gold dissolution: towards understanding of noble metal corrosion. RSC Advances. 3, 1651616527 (2013).

55. Y. Yoon, B. Yan, Y. Surendranath, Suppressing Ion Transfer Enables Versatile Measurements of Electrochemical Surface Area for Intrinsic Activity Comparisons. J. Am. Chem. Soc. 140, 2397-2400 (2018).

56. C. Korzeniewski, B. E. Conway, in Proceedings of the Symposium on the Electrochemical Double Layer (The Electrochemical Society, 1997), vol. 97 of Electrochemical Society Proceedings, pp. 349-350.

57. P. Chen, H.-B. Zhang, G.-D. Lin, Q. Hong, K. R. Tsai, Growth of carbon nanotubes by catalytic decomposition of $\mathrm{CH}_{4}$ or $\mathrm{CO}$ on a Ni/MgO catalyst. Carbon. 35, 1495-1501 (1997).

58. E. Wiberg, A. F. Holleman, N. Wiberg, in Inorganic Chemistry (Academic Press, 2001), pp. 810-811.

59. P. Basu, in Biomass Gasification, Pyrolysis and Torrefaction (Third Edition), P. Basu, Ed. (Academic Press, 2018;

https://www.sciencedirect.com/science/article/pii/B9780128129920000078), pp. 211-262.

60. S. Greenfield, M. Clift, Analytical Chemistry of the Condensed Phosphates (Pergamon, Oxford, 1975).

61. T. Engel, P. Reid, Thermodynamics, Statistical Thermodynamics, \& Kinetics: Pearson New International Edition (Pearson, Harlow, 3rd edition., 2013), p. 546.

62. M. Williams, in The Merck Index: An Encyclopedia of Chemicals, Drugs, and Biologicals, M. J. Neil, Ed. (Royal Society of Chemistry, Cambridge, UK, ed. 15th, 2013), vol. 74, p. 1266.

63. J. C. Southard, R. A. Nelson, The Vapor Pressure of Phosphorus Pentoxide. J. Am. Chem. Soc. 59, 911-916 (1937).

64. A. T. D. Butland, R. J. Maddison, The specific heat of graphite: An evaluation of measurements. Journal of Nuclear Materials. 49, 45-56 (1973).

65. J. G. Speight, Environmental Organic Chemistry for Engineers (Butterworth-Heinemann, 2016). 
66. E. P. Egan, B. B. Luff, Heat of solution of orthophosphoric acid. J. Phys. Chem. 65, 523-526 (1961).

67. M. E. Walsh, C. M. Collins, C. H. Racine, Persistence of white phosphorus $\left(\mathrm{P}_{4}\right)$ particles in salt marsh sediments. Environ. Toxicol. Chem. 15, 846-855 (1996).

68. W. McCabe, J. Smith, P. Harriott, Unit Operations of Chemical Engineering (McGraw-Hill Education, Boston, 7th edition., 2004), p. 454.

Acknowledgments: The authors gratefully acknowledge Jaeyune Ryu, Ryan Bisbey, Thejas Wesley, James Connor Gilhula, Alex Radosevich, Mircea Dincă, Antoine Allanore, Christopher Colin "Kit" Cummins, and Cyrille Costentin for many insightful discussions.

\section{Funding:}

Université Mohammed VI Polytechique-MIT Research Program (UMRP) Partnership for Progress on Sustainable Development in Africa (YS, AJL, JFM)

Tata Fellowship, MIT Tata Centre for Technology \& Design (JFM)

National Defense Science \& Engineering Graduate Fellowship, U.S. Department of Defense (AJL)

\section{Author contributions (CRediT):}

Conceptualization: AJL, JFM, YS

Data curation: JFM

Formal Analysis: JFM

Funding acquisition: YS

Investigation: AJL (supporting), JFM (lead)

Methodology: AJL, JFM

Project administration: YS

Resources: YS

Supervision: YS

Validation: JFM

Visualization: AJL (supporting), JFM (lead), YS

Writing - original draft: JFM

Writing - review \& editing: AJL (supporting), JFM, YS

Competing interests: The authors declare the following competing financial interest: AJL and YS are inventors on patent application WO2020061551A1, submitted by the Massachusetts Institute of Technology, that covers the process of molten metaphosphate electrolysis for production of white phosphorus described in this work.

Data and materials availability: All data are available in the main text or the supplementary materials. 
Additional Author notes: YS, AJL, and JFM conceived of the project. AJL designed the high-temperature electrochemical reactor used in this study and collected anode-gas GC data,

${ }^{31} \mathrm{P}$ NMR for $\mathrm{P}_{4}$ in $\mathrm{CS}_{2}$, and preliminary voltammetric and current-overpotential data on

metaphosphate melts. JFM collected all final electrochemical data sets, comprising phosphate Faradaic efficiency experiments, current-overpotential studies, red phosphorus product dosing experiments, and anhydride dependence studies, as well as performing computational electrochemical simulations. YS assisted with experimental design and data interpretation. JFM and YS drafted and edited the manuscript, with input from AJL.

\section{Supplementary Materials}

Materials and Methods

Supplementary Text

Figs. S1 to S18

Tables S1 to S8 